\title{
LA EXPANSIÓN DE LAS FRANQUICIAS EN ESPAÑA
}

POR

AGUSTÍN GÁMIR Y RICARDO MÉNDEZ

La expansión de las franquicias

Una de las nuevas formas de distribución que mayor dinamismo ha registrado durante los últimos años es, sin duda, la franquicia. Junto a las definiciones disponibles en los numerosos textos que abordan el fenómeno desde una perspectiva empresarial (Bolea, A., 1990; Alonso Prieto, M., 1997; Raab, S. S.-Matusky,G., 1997; Díez de Castro, E.-Galán, J. L., 1998...), debe mencionarse la que aparece en la Ley 7/1999 de Ordenación del Comercio Minorista, que la identifica como «aquella que se realiza en virtud de un contrato, por el cual una empresa, el franquiciador, cede a otra, el franquiciado, a cambio de una contraprestación financiera directa o indirecta, el derecho a la explotación de una franquicia para comercializar determinados tipos de productos o de servicios y que comprende, por lo menos: el uso de una denominación o rótulo común, y una presentación uniforme de los locales o de los medios de transporte objeto del contrato; la comunicación por el franquiciador al franquiciado de un saber hacer, y la prestación contínua por el franquiciador al franquiciado de asistencia comercial o técnica durante la vigencia del acuerdo». Se trata, pues, de un método de colaboración formalizado entre empresas independientes, razón por la que suele integrarse como una de las formas más características hoy de comercio drid.

Agustín Gámir y Ricardo Méndez, Universidades de Salamanca y Complutense de Ma-

Estudios Geográficos

Tomo LXI, 2000, n. ${ }^{\circ} 238$, enero-marzo 
asociado (Parra, F. et al., 1996), en el que caben multitud de situaciones diferenciadas en función de las características empresariales, la rama de actividad a que pertenezcan, o el tipo de relaciones específicas entre los participantes.

La aparición y desarrollo de cadenas de franquicias constituye un fenómeno reciente en la mayoría de países, que registra hoy un crecimiento casi exponencial y una rápida difusión territorial. Si se utiliza la metáfora del ciclo de vida, podría hablarse de una fórmula que aún se encuentra en su fase de juventud, cuando el número de competidores en la mayoría de sectores es aún limitado, pero las tasas medias de beneficios resultan ya suficientemente elevadas como para atraer a un creciente número de imitadores. Sólo desde noviembre de 1998 se estableció en España un Registro de Franquiciadores, cuya gestión se delega en las Comunidades Autónomas.

En la justificación de ese indudable dinamismo que, pese a la existencia de cierta rotación empresarial, hace posible la sucesión de saldos anuales altamente positivos en todos los casos estudiados por la bibliografía internacional, se suman diversos factores, que han sido profusamente reiterados por los analistas y publicistas de esta fórmula:

- Para la empresa franquiciadora, se trata de un sistema que posibilita una rápida expansión y el acceso a nuevos mercados mediante la venta de licencias, con un coste y unos riesgos bastante inferiores a los que conllevaría su implantación directa, con lo que también se reducen la inversión inicial de capital fijo y la plantilla laboral propia.

- Por su parte, la empresa franquiciada se beneficiará de la imagen corporativa y de marca que puede ofrecerle una empresa ya consolidada y con experiencia en el sector, además de acceder al conocimiento de las técnicas de gestión y métodos profesionalizados de venta que forman parte del saber hacer que el franquiciador debe transmitirle, aprovechar la aparición de economías de escala en sus aprovisionamientos, y gozar de una explotación exclusiva de tales derechos en un área determinada. Todo ello puede permitirle superar con éxito algunas de las dificultades a que se enfrenta el pequeño comercio minorista independiente, razón que explicaría la desigual trayectoria de ambos.

Esa acumulación de ventajas justifica la valoración positiva que domina con rotundidad en la bibliografía reciente sobre la materia, llegán- 
dose hasta la afirmación de que la franquicia «es un concepto revolucionario, que puede solucionar los problemas de una distribución anticuada, tanto para el fabricante o mayorista, como para el detallista» (Flechoso, J. J., 1997, 20). Una visión tan plana y lineal como ésta adolece de evidentes deficiencias, tanto al ignorar las limitaciones y costes inherentes a este sistema de distribución, como al mantener una perspectiva micro, que no interpreta el significado que pueda tener la expansión de las cadenas de franquicias en el contexto del cambio estructural inherente a la actual fase de capitalismo global (Méndez, R., 1997), además de marginar las implicaciones del fenómeno en la formalización de un espacio de redes (Castells, M., 1997; Gutiérrez Puebla, J., 1998).

\section{Las cadenas de franquicias en la reestructuración} del sistema de distribución.

a) La franquicia como vector de globalización para el comercio y los servicios. Las actuales transformaciones estructurales que afectan a los sistemas productivos y de distribución, junto a ciertas alteraciones en las características y el comportamiento de los consumidores, han dado lugar a una modernización de las estructuras y estrategias empresariales, que afecta tanto a su tamaño interno, como a sus relaciones mutuas, los tipos de establecimientos o sus pautas de localización (Salgueiro, T. B., 1996). Desde esa perspectiva, la franquicia puede entenderse como una respuesta coherente a las nuevas condiciones imperantes, que aproxima el funcionamiento del comercio minorista y de ciertos servicios al del sector productivo.

Así, el crecimiento de las franquicias se ha convertido en uno de los vehículos más poderosos para impulsar una creciente internacionalización de estas actividades, que siempre se caracterizaron por su particular vinculación a mercados locales, en contacto directo con sus clientes. El constante aumento en el número de sociedades que aplican estrategias globales se justifica tanto por la búsqueda de nuevos mercados, como por los beneficios derivados de la obtención de economías de escala, o la creación de una demanda interna a la propia red empresarial, que reduce el impacto de las fluctuaciones cíclicas en la demanda externa (Benko, G., 1996; Dicken, P., 1998). La franquicia resulta, pues, un magnífico exponente de esas nuevas formas de inversión que, frente a las clásicas po- 
líticas empresariales de crecimiento interno (creación de nuevas filiales), o externo (compra de empresas en otros países), sustituyen la aportación directa de capital por alianzas estratégicas y vinculaciones entre compañías independientes. Eso permite penetrar con rapidez en un número creciente de mercados nacionales sin exigir previamente una gran dimensión propia, además de aprovechar el mayor y mejor conocimiento del entorno que aportan las empresas autóctonas.

En consecuencia, la constitución de cadenas de franquicias se ha convertido también en un vehículo para la difusión internacional de ciertas pautas culturales y de consumo de masas a partir de sus respectivos países de origen, superpuestas a las de los lugares en que se asientan, si bien con frecuencia parece más adecuado hablar de una transmisión de estereotipos simplificados que de una verdadera convergencia de hábitos y comportamientos.

b) La franquicia como impulsora de la innovación en sectores tradicionales. Una de las ventajas competitivas de que disfrutan numerosas cadenas de franquicias frente al comercio y los servicios tradicionales, radica en el impulso a la innovación que, con frecuencia, puede asimilarse a esta fórmula. No puede, por ello, ignorarse su contribución actual a la renovación de actividades donde el peso de la inercia y la escasez de recursos limitaron el aumento de productividad y la posibilidad de una gestión más profesionalizada.

Por una parte, tiene lugar una verdadera innovación en los procesos inherentes a la distribución, destinada tanto a reducir costes como a aumentar su flexibilidad interna ante la inestable evolución de la demanda. La externalización de tareas que supone la concesión de licencias a operadores independientes para que desarrollen su negocio y lleven a cabo una relación directa con los clientes, mientras el franquiciador reorienta su actividad dando mayor protagonismo a las funciones de coordinación, es el mecanismo de mayor importancia para lograr ese objetivo. Al tiempo, la mayor capacidad conjunta que esa colaboración supone para invertir en actividades de I+D, diseño, marketing, publicidad, etc., permite la renovación en el contenido o la imagen de ciertos productos, además de impulsar una informatización creciente, tanto de la logística como de las ventas, capaz de asegurar una destacada presencia de las franquicias en los nuevos ámbitos de la telecompra y el teleservicio (Gámir, A., 1997). 
Por otra, la franquicia debería actúar también como vehículo para la innovación en la gestión de las empresas participantes, mediante las tareas de formación permanente que debe realizar el franquiciador, el mantenimiento de densos flujos de información entre los miembros de la cadena y la realización de actuaciones coordinadas. Eso puede contribuir al éxito mayoritario de una fórmula en la que se integra un elevado porcentaje de nuevos empresarios sin experiencia previa en el sector, con un perfil definido por una edad media relativamente baja, nivel de estudios superior al promedio y destacada presencia de la mujer, al menos por los datos disponibles en Portugal o España (Salgueiro, T. B., 1996; Barbadillo Asociados, 1998).

c) La franquicia como red jerárquica de empresas. Un debate habitual en los últimos tiempos es el que enfrenta a quienes observan la creciente hegemonía de la gran empresa integrada, frente a los que destacan las nuevas oportunidades abiertas a la pequeña empresa. Si en el plano industrial las tendencias descentralizadoras otorgaron un protagonismo creciente a las PYMEs, en el comercial han sido frecuentes las referencias al creciente poder ejercido por las grandes cadenas de distribución y las grandes superficies comerciales, frente al pequeño y fragmentado comercio minorista (Dawson, J. A. edit., 1980; Dawson, J. A.Burt, S. L., 1988; Carreras, C., 1990). Esa visión dicotómica de las tendencias actuales en la evolución de las estrategias empresariales ofrece una visión sólo parcial de las tendencias en curso, tal como pone de manifiesto el análisis sobre las cadenas de franquicias. Frente a la sustitución de una forma organizativa por otra, lo más significativo aquí es la integración de ambas dentro de una estructura reticular, en donde coexisten y se complementan empresas-red franquiciadoras con establecimientos múltiples, a veces en varios países, y redes de empresas franquiciadas, que dependen funcionalmente de las anteriores (Belussi, F. edit., 1992; Veltz, P., 1993).

La franquicia supone, por tanto, la consolidación de redes empresariales constituidas tan sólo por dos o, a lo sumo, tres niveles (cuando existen franquicias master, que actúan como representantes de la enseña en un país determinado), caracterizadas por una fuerte jerarquización de los flujos de decisión que circulan por su interior. De este modo, frente al canto a la empresarialidad y al desarrollo de la iniciativa personal que, con frecuencia, acompaña su imagen y la aproximan a la de ese capitalismo 
popular de pequeños empresarios autónomos que operan en un mercado de competencia casi perfecta, las cadenas de franquicias están sometidas a un fuerte control interno y a ciertas restricciones a la competencia que, en ocasiones pueden generar, incluso, problemas de carácter legal.

Por una parte, las condiciones impuestas por el franquiciador en los contratos son una buena muestra de esas relaciones de dependencia e intercambio desigual entre sus participantes. Así, resulta frecuente la obligación de realizar un cierto volumen anual de compras al franquiciador, la imposición de determinados proveedores, el control de caja y de la gestión comercial, el pago de un canon de publicidad por el franquiciado para financiar las campañas de la firma, o la existencia de fuertes restricciones relativas al emplazamiento y características de los locales. También se constata la posibilidad de rescindir esos contratos de forma unilateral si el franquiciador está descontento con la actuación de algún franquiciado, sin que sea necesario hacerlo de mutuo acuerdo. En resumen, desde el punto de vista de su estructura interna, la franquicia hace posible una fuerte centralización de las decisiones y, con ello, del poder, combinada con una no menos intensa descentralización/externalización de la actividad y los riesgos, con lo que consigue una elevada flexibilidad.

d) La franquicia como factor de estandarización en las pautas de consumo. Frente al elogio de la diversidad propia de la condición posmoderna, que ensalza la superación del consumo de masas en beneficio de un consumo individual de masas, mejor adaptado a las exigencias y necesidades de los individuos, la franquicia parece impulsar un movimiento de sentido contrario, más cercano a una verdadera industrialización de los servicios, lo que la incorpora al debate sobre el significado y caracterización de las nuevas pautas y espacios del consumo (Harvey, D., 1990; García Ballesteros, A., 1998).

En este caso, el objetivo prioritario suele ser la búsqueda de la máxima homogeneidad posible, que transmita una imagen de marca perfectamente reconocible por el cliente y haga así totalmente predecible su consumo. Ese deseo de homogeneización incluye desde las características de los productos o servicios que se ofrecen, a su precio, el mobiliario y decoración de los locales, la uniformación de los empleados (cuando existe), la atención al cliente, el tipo de publicidad, o la relación con proveedores, bancos, etc. La existencia de manuales de franquicia propios de 
cada enseña, guardados celosamente como parte de su patrimonio y transmitidos tan sólo a los miembros de la misma, se convierte en instrumento útil para la concreción de esas señas de identidad corporativas, junto con los cursos y seminarios impartidos de forma periódica.

El resultado final será una progresiva estandarización en un tipo de actividades donde tradicionalmente primaron la diversidad y la búsqueda de identidad propia por parte de cada empresa para atraer la atención de cierto tipo de clientes, y esa misma reducción de la variedad se transmite a los espacios de consumo. La presencia creciente en nuestras ciudades de tiendas pertenecientes a estas cadenas, que reproducen de forma clónica la misma imagen externa en localizaciones también muy similares, con tendencia a agruparse en determinadas áreas, es su consecuencia directa, que alcanza su mejor expresión en los centros comerciales integrados de carácter suburbano.

e) La franquicia como factor de jerarquización y nuevos contrastes territoriales. Una de las características del comercio minorista y las actividades de servicios al consumo es su localización relativamente dispersa, muy dependiente de la correspondiente a la población que abastecen. Por el contrario, cualquier análisis sobre la organización espacial de las franquicias permite constatar una distribución territorial más selectiva y concentrada, que contribuye a reforzar contrastes previos, tanto cuantitativos como cualitativos.

Por lo que hace referencia a los franquiciadores, la mayor parte de las enseñas ha surgido en espacios que pueden calificarse funcionalmente como centrales (países desarrollados, áreas metropolitanas...), pues es en ellos donde se sitúan buena parte de las empresas más consolidadas que pueden dar origen a una red, así como las que cuentan con mayor conocimiento e información sobre las posibilidades que ofrece esta fórmula y están dispuestas a correr el riesgo que supone toda innovación. A partir de esos focos originarios, tiene lugar un proceso de difusión, tanto jerárquica como por contigüidad, en dirección a espacios dinámicos y con amplios mercados en expansión (países semiperiféricos, ciudades medias, áreas turísticas...), ampliando las áreas afectadas por la aparición de este fenómeno.

Con referencia a los establecimientos franquiciados, pueden apuntarse un par de tendencias espaciales frecuentemente contrastadas. Por un lado, persisten ciertos comportamientos de tipo christalleriano en la inter- 
pretación del espacio comercial por parte de numerosas empresas franquiciadoras. A escala interurbana, se concede especial importancia al tamaño mínimo de población (umbral de demanda) existente en el núcleo urbano a la hora de conceder una franquicia. Junto al simple número de consumidores, se presta también atención a otras características complementarias como nivel de renta, estructura por edades, hábitos de consumo, tasa de motorización, etc., factores todos ellos que tienden a excluir a las áreas rurales, convirtiendo a la franquicia en un fenómeno esencialmente urbano. La elección de emplazamiento se basa en criterios de accesibilidad, visibilidad y coste, concediéndose la exclusividad para la explotación de la marca dentro de un área de mercado cuya dimensión se establece en función del alcance o radio de influencia de los bienes/servicios ofrecidos y la distribución de la población. A escala intraurbana, la selectividad espacial es también la norma, con una especial atracción hacia las áreas peatonales y grandes avenidas del centro de negocios o los barrios residenciales de mayor renta, junto a los grandes centros comerciales suburbanos, donde la complementariedad genera externalidades que refuerzan el atractivo de cada establecimiento. Así, frente a las decisiones de localización del pequeño comercio minorista, muy influidas por la inercia, el conocimiento directo del entorno, o una valoración del espacio sesgada por una fuerte carga subjetiva e intuitiva, las del comercio franquiciado parecen más guiadas, en general, por criterios de racionalidad económica que se apoyan en estudios previos de mercado, razón por la que el recurso a los SIG como instrumento útil para determinar buenos emplazamientos aparece cada vez más citado por los propios franquiciadores.

El resultado es la formalización de un espacio de redes, constituido por un creciente número de nodos jerarquizados, especializados en actividades diversas e interconectados por una densa malla de flujos, tanto materiales como inmateriales, que resalta el valor estratégico de ciertos lugares, mientras deja otros sumergidos o en sombra (Veltz, P., 1998), excluidos de los beneficios potenciales del nuevo modelo de articulación territorial.

\section{Las franquicias en España}

La franquicia es, por el momento, una forma de organización empresarial relativamente incipiente en España, que afecta sobre todo a la 
distribución de ciertos productos y servicios y que se extiende con rapidez en los últimos años hasta convertirse en un fenómeno emergente, cuyos efectos resultan cada vez más visibles en el paisaje urbano. Para abordar su estudio se han consultado diferentes Guias de Franquicias publicadas en España en 1998, que presentan una estructura muy similar en cuanto a la información disponible, aunque el número de empresas registrada es diferente en cada caso. Se elaboró así una base de datos propia, que superpone la información obtenida en las guías editadas por las empresas consultoras Tormo Asociados y Barbadillo Asociados, junto a la procedente de la Asociación Española de Franquiciadores, con lo que se ha conseguido identificar un número mayor de empresas que cualquiera de ellas, si bien con la contrapartida de ciertas imprecisiones por falta de datos en algunos apartados. De modo complementario, también se tuvo acceso a las guías publicadas por la Cámara Oficial de Comercio e Industria de Madrid, y a los Informes de Situación de la Franquicia en España, realizados por Barbadillo Asociados en 1996 y 1998, a partir de la encuesta a una muestra de enseñas. Aunque la falta de un censo o directorio oficial introduce un cierto margen de error en la información manejada, que deberá ser objeto aún de cierta mejora además de ser ampliada mediante encuestas y entrevistas a los agentes protagonistas, los resultados obtenidos parecen ofrecer una fiabilidad y significación suficientes como para poder considerarse un primer diagnóstico abordado desde una perspectiva territorial.

a) Evolución reciente e importancia actual de las franquicias. España se incorporó al desarrollo de las franquicias con cierto retraso en relación a otros países del entorno, por lo que puede afirmarse que, si bien sus orígenes son más remotos, se trata, en esencia de una realidad propia de los años noventa.

Por una parte, en 1980 tan sólo existían unas 40 franquicias, en su mayoría de procedencia exterior, que pasaron a ser más de 150 al finalizar la década, para llegar a las 684 contabilizadas en 1997, tras contrastar la información de las diferentes Guías de Franquicias. Entre estas últimas, un $80 \%$ de las cadenas se constituyeron a partir de 1990 , y más de la mitad ( $54 \%$ del total) lo hicieron en los cuatro últimos años. La extrema juventud de la pirámide de edades, resultado conjunto del origen reciente de la mayoría de franquicias y de una rotación entre sus componentes, supone cierta inmadurez del proceso, perfectamen- 
te visible en algunas de las características que serán objeto de comentario más adelante.

Esas 684 enseñas controlan ya un total de 22.846 establecimientos dentro del territorio español, que duplican los existentes sólo dos años antes, además de otros 233.000 más allá de nuestras fronteras, al integrarse en bastantes casos dentro de grandes grupos transnacionales del sector de la distribución, desde McDonald's o Benetton, a Western Union, Kentucky Fried Chicken, etc. Aunque resulta difícil obtener datos fiables sobre su actividad económica, los informes realizados por Barbadillo Asociados permiten estimar en unos 53.000 el volumen total de empleos directos generados en España (menos de 20.000 en las franquiciadoras). Por su parte, aunque la cifra de negocios supera ampliamente el medio billón de pesetas (562.000 millones de pesetas en 1997), su importancia relativa resulta aún bastante modesta, pues tan sólo representa un $5 \%$ del P.I.B. generado por el sector de la distribución, muy por debajo aún del $25 \%$ que alcanza en otros países europeos donde el proceso es más antiguo y ha alcanzado ya una cierta madurez (Husson-Dumoutier, A.-Olivier, B., 1993).

b) Una creciente diversidad sectorial y empresarial. El fenómeno de la franquicia, que conoció sus primeras fases de desarrollo en Estados Unidos, asociado a sectores específicos como los restaurantes de comida rápida, los servicios de asistencia al automóvil, las tintorerías/lavanderías y ciertas tiendas especializadas en la venta de ropa, productos de perfumería y cosmética, etc., ha dejado ya de ser patrimonio exclusivo de unas pocas actividades para difundirse a un conjunto cada vez mayor y más heterogéneo.

Cuadro I

ESTRUCTURA DE LAS FRANQUICIAS POR RAMAS DE ACTIVIDAD EN 1997

\begin{tabular}{lcccc}
\hline \multicolumn{1}{c}{ Ramas de actividad } & $\mathbf{N}^{\mathbf{0}}$ Enseñas & \% Total & $\begin{array}{c}\mathbf{N}^{\mathbf{0}} \text { Estable- } \\
\text { cimientos }\end{array}$ & \% Total \\
\hline Confección & 108 & 16,3 & 1.840 & 8,1 \\
Hostelería/restauración & 98 & 14,8 & 2.704 & 11,9 \\
Tiendas especializadas & 90 & 13,6 & 2.021 & 8,9
\end{tabular}


CUADRo I (continuación)

ESTRUCTURA DE LAS FRANQUICIAS POR RAMAS DE ACTIVIDAD EN 1997

\begin{tabular}{lccrr}
\hline \multicolumn{1}{c}{ Ramas de actividad } & No Enseñas & \% Total & $\begin{array}{c}\text { No Estable- } \\
\text { cimientos }\end{array}$ & \%otal \\
\hline Servicios especializados & 82 & 12,3 & 3.681 & 16,2 \\
Consultoría/inmobiliarias & 40 & 6,0 & 1.016 & 4,5 \\
Alimentación & 27 & 4,1 & 2.711 & 11,9 \\
Enseñanza & 25 & 3,8 & 825 & 3,6 \\
Tintorería/limpieza & 24 & 3,6 & 930 & 4,1 \\
Servicios del automóvil & 23 & 3,5 & 935 & 4,1 \\
Belleza & 23 & 3,5 & 528 & 2,3 \\
Informática & 22 & 3,3 & 859 & 3,8 \\
Imprenta/papelería & 22 & 3,3 & 1.373 & 6,1 \\
Cosmética/parafarmacia & 19 & 2,9 & 551 & 2,4 \\
Agencias viajes/hoteles & 19 & 2,9 & 778 & 3,4 \\
Mobiliario & 17 & 2,6 & 348 & 1,5 \\
Transporte/mensajería & 12 & 1,8 & 1.117 & 4,9 \\
Joyería & 7 & 1,1 & 163 & 0,7 \\
Deportes & 6 & 0,9 & 309 & 1,4 \\
\multicolumn{1}{c}{ Total } & & & & \\
\hline
\end{tabular}

Fuente: Guías de Franquicias 1998, y elaboración propia.

Si se excluyen las franquicias de producción, que venden objetos de fabricación propia y que en España son bastante escasas, tanto las franquicias de distribución de productos, como las de servicios, muestran una importancia similar, pero el protagonismo de algunas de esas actividades tradicionales aún se mantiene. Así, tal como muestra el cuadro I, el mayor volumen de enseñas sigue correspondiendo a las tiendas de confección y la hostelería/restauración, con presencia destacada del fast food, que casi representan en conjunto una tercera parte de las franquicias y el $20 \%$ de los locales. Aquí coexisten grandes cadenas internacionales, sobre todo estadounidenses (McDonald's, Burger King, Pizza Hut, Dunkin Donuts, Subway, Levi's...), y algunas europeas (Benetton, Rodier, Lacoste...), con empresas de capital español que han experimentado un rápido crecimiento, hasta el punto de abrir establecimientos en otros países (Te- 
lepizza, Pans \& Company, Mango, Cedosce, Don Algodón, Springfield...), y pequeñas firmas con un ámbito de actuación territorial también reducido.

Esa misma heterogeneidad caracteriza las estructuras empresariales, que pueden analizarse desde la perspectiva del tamaño que presentan las firmas existentes, el origen del capital o las relaciones entre franquiciadores y franquiciados.

Respecto a la dimensión de las cadenas, lo más destacable es su carácter minifundista, pese a la presencia de algunos líderes mundiales en su respectivo sector. Así, las cadenas implantadas en España cuentan con un promedio de 33,4 establecimientos, sumando los propios y los franquiciados, pero esa cifra resulta un simple artificio estadístico, resultado de la presencia de unas pocas que cuentan con un número muy elevado y provocan el consiguiente sesgo: las 57 franquicias que superan los 100 locales, un $8,4 \%$ del total, reúnen una cifra global de 12.168 establecimientos, el 53,3\% de los existentes. Más de la mitad de las enseñas (297), en cambio, no alcanzan siquiera la decena de locales, y un $24 \%$ no supera los cinco, cifras que pueden relacionarse con la debilidad o el origen aún muy reciente de muchas de ellas, que están lejos aún de haber alcanzado su fase de madurez. En esa misma línea, la mitad de las empresas franquiciadoras abrieron tan sólo una unidad piloto antes de crear la cadena, y en una proporción similar su experiencia previa no llegaba a los dos años, lo que contradice algunos de los supuestos que la teoría les asigna y constituye otro factor de fragilidad para el desarrollo futuro de esas iniciativas. Finalmente, la cifra de facturación media por cadena se situó entre los 100 y 200 millones de pesetas, aunque con grandes diferencias entre los extremos, suponiendo en conjunto un volumen de negocio estimado de 562.107 millones de pesetas en 1997.

Con relación a los establecimientos, su reducido tamaño medio y la amplia dispersión respecto a esa cifra son también ampliamente dominantes, pues mientras un $49,7 \%$ de los franquiciados requieren una superficie media comprendida entre 25 y 125 metros cuadrados, junto a una inversión inicial inferior a los 20 millones de pesetas, existe un reducido grupo donde esa barrera de entrada resulta bastante superior, tal como ocurre en 21 casos donde las exigencias superan los 50 millones de inversión y los 200 metros cuadrados de local; en el extremo opuesto, un total de 29 franquicias no exigen local, por tratarse de actividades que pueden realizarse a domicilio. 
Por lo que hace referencia al origen del capital perteneciente a las empresas franquiciadoras, puede destacarse la rápida difusión del fenómeno entre los empresarios españoles, que son ya amplia mayoría, tanto en el número de enseñas como en el de establecimientos controlados por las mismas (cuadro II). Aunque las cifras pueden estar sobrevaloradas por la presencia de algunas franquicias master, que aparecen identificadas como españolas cuando son simples representaciones de empresas originarias de otros países, el resultado es prácticamente idéntico al del último informe de situación realizado mediante encuesta por Barbadillo Asociados (73,3\%).

CUADRo II

FRANQUICIAS EXISTENTES EN 1997, SEGÚN PAÍS DE ORIGEN

\begin{tabular}{lrrrr}
\hline \multicolumn{1}{c}{ País de origen } & $\begin{array}{c}\text { No }^{\text {Franqui- }} \\
\text { ciadores }\end{array}$ & \% Total & $\begin{array}{c}\text { No Estable- } \\
\text { cimientos }\end{array}$ & \%otal \\
\hline España & 511 & 74,71 & 17.965 & 78,63 \\
Estados Unidos & 44 & 6,43 & 1.694 & 7,41 \\
Francia & 37 & 5,41 & 1.059 & 4,64 \\
Italia & 22 & 3,22 & 551 & 2,41 \\
Reino Unido & 13 & 1,90 & 383 & 1,68 \\
Bélgica & 5 & 0,73 & 59 & 0,26 \\
Dinamarca & 4 & 0,58 & 64 & 0,28 \\
Suecia & 3 & 0,44 & 2 & 0,01 \\
Andorra & 2 & 0,29 & 9 & 0,04 \\
Suiza & 2 & 0,29 & 66 & 0,29 \\
Otros & 8 & 1,20 & 306 & 1,34 \\
Sin datos & 33 & 4,82 & 688 & 3,01 \\
& & & & \\
\multicolumn{1}{c}{ Total } & 684 & 100 & 22.846 & 100 \\
\hline
\end{tabular}

Fuente: Guías de Franquicias, 1998.

De las franquicias procedentes del exterior, que suman un total de 140 , son amplia mayoría las de origen estadounidense, francés e italiano (104 franquicias y 3.472 establecimientos), junto con las de los restantes países de la Unión Europea ( 28 franquicias y 586 establecimientos). Aún sin definir una especialización nítida a favor de ciertas actividades, su pre- 
sencia resulta particularmente característica en los ámbitos de la restauración, las consultoras e inmobiliarias, los servicios del automóvil, las tintorerías, las tiendas y servicios especializados, o la moda, siendo de esperar una creciente penetración en otras actividades durante los próximos años. Respecto a las franquicias de origen español, mientras la encuesta de 1996 cifraba en un 19\% las que desarrollaban alguna actividad en el exterior, la publicada en 1998 eleva esa proporción al 31\%, con una clara orientación hacia los países limítrofes como Portugal (60\% de los casos) y Francia (52,5\%), junto a Latinoamérica $(47,5 \%)$ y los restantes estados de la Unión Europea (40,0\%), donde la forma de implantación más habitual es ya la franquicia master (42,5\% de las empresas).

Finalmente, por lo que se refiere a los contratos de franquicia, su duración habitual es de cinco años, con posibilidad de renovación en más del $80 \%$ de los casos. Los servicios a que se comprometen los franquiciadores afectan, sobre todo, a la formación de los franquiciados $(87,8 \%$ de los encuestados), el marketing y la publicidad (83,3\%), el asesoramiento en la gestión (78,9\%) y el aprovisionamiento de productos $(75,0 \%)$, cobrando en contraprestación un canon inicial que oscila entre 0,5 y 2 millones de pesetas, junto a un pago anual en torno al 5\% de las ventas totales. Además, el franquiciador se reserva la exclusividad en la oferta de productos $(69,4 \%$ de las franquicias) y de servicios $(56,1 \%)$, así como la posibilidad de establecer controles periódicos, cediendo a cambio la explotación exclusiva de un territorio delimitado a cada franquiciado en el 87,2\% de los casos (Barbadillo Asociados, 1998).

\section{Organización espacial de las cadenas de franquicias en España}

En una panorámica de conjunto como la aquí planteada, la distinción básica es la existente entre la localización de las empresas franquiciadoras, dominada por una fuerte polarización, y la de los establecimientos franquiciados, aparentemente más dispersa, pero no por ello carente de una selectividad bastante estricta en cuanto a los criterios que guían la toma de decisiones, lo que establece diferencias respecto al comercio minorista tradicional.

a) Localización de las empresas franquiciadoras. El surgimiento a partir de iniciativas endógenas, o la instalación de empresas franqui- 
ciadoras procedentes del exterior es, ante todo, un fenómeno urbano-metropolitano, relacionado de forma directa con el tamaño y el dinamismo de las ciudades, generadores de externalidades positivas. Esa relación se traduce en una concentración de las empresas matrices en aquellos territorios más poblados, urbanizados y con elevado nivel de renta/consumo, así como con una amplia dotación de servicios a las empresas.

A escala regional (cuadro III), las franquiciadoras reúnen más de dos tercios de sus efectivos (468 empresas, el 69,23\%) en Madrid y Cataluña, desde donde controlan un total de 17.956 establecimientos, equivalentes al 78,60\% de los existentes, al radicarse aquí la dirección de la mayoría de

CUADRo III

DISTRIBUCIÓN REGIONAL DE LAS CADENAS DE FRANQUICIAS EN ESPAÑA

\begin{tabular}{|c|c|c|c|c|c|}
\hline CC.AA. & $\begin{array}{c}\text { A } \\
\text { \% Empresas } \\
\text { franquicia- } \\
\text { doras }\end{array}$ & $\begin{array}{c}\text { B } \\
\text { \% Estable- } \\
\text { franquicia- } \\
\text { dos }\end{array}$ & 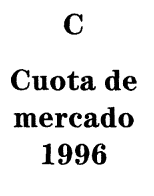 & $\begin{array}{c}D \\
\text { Índice } \\
\text { actividad } \\
\text { económica } \\
1996\end{array}$ & $\begin{array}{c}\text { B } \\
\text { Cociente } \\
\text { de locali- } \\
\text { zación }\end{array}$ \\
\hline Andalucía & 5,47 & 10,24 & 16,71 & 12,56 & 0,61 \\
\hline Aragón & 4,00 & 2,86 & 3,16 & 3,56 & 0,90 \\
\hline Asturias & 1,48 & 1,99 & 2,61 & 2,60 & 0,76 \\
\hline Baleares & 1,62 & 3,13 & 2,27 & 2,16 & 1,38 \\
\hline Canarias & 0,74 & 4,42 & 4,10 & 3,35 & 1,08 \\
\hline Cantabria & 0,89 & 1,90 & 1,30 & 1,17 & 1,46 \\
\hline Castilla-La Mancha & 0 & 2,14 & 4,36 & 3,41 & 0,49 \\
\hline Castilla-León & 2,81 & 3,87 & 6,34 & 5,90 & 0,61 \\
\hline Cataluña & 33,73 & 31,69 & 16,64 & 20,43 & 1,90 \\
\hline Comun. Valenciana & 7,69 & 8,92 & 10,41 & 10,17 & 0,86 \\
\hline Extremadura & 0,15 & 1,33 & 2,60 & 1,92 & 0,51 \\
\hline Galicia & 1,33 & 3,46 & 6,59 & 5,73 & 0,52 \\
\hline Madrid & 35,50 & 14,92 & 12,63 & 14,15 & 1,18 \\
\hline Murcia & 0,15 & 2,03 & 2,67 & 2,37 & 0,76 \\
\hline Navarra & 0,89 & 1,14 & 1,46 & 2,13 & 0,78 \\
\hline País Vasco & 3,40 & 5,23 & 5,12 & 7,39 & 1,02 \\
\hline La Rioja & 0,15 & 0,73 & 0,73 & 0,78 & 1 \\
\hline Total & 100 & 100 & 100 & 100 & 1 \\
\hline
\end{tabular}

Fuente: Guías de Franquicias, Barbadillo Asociados, La Caixa, y elaboración propia. 


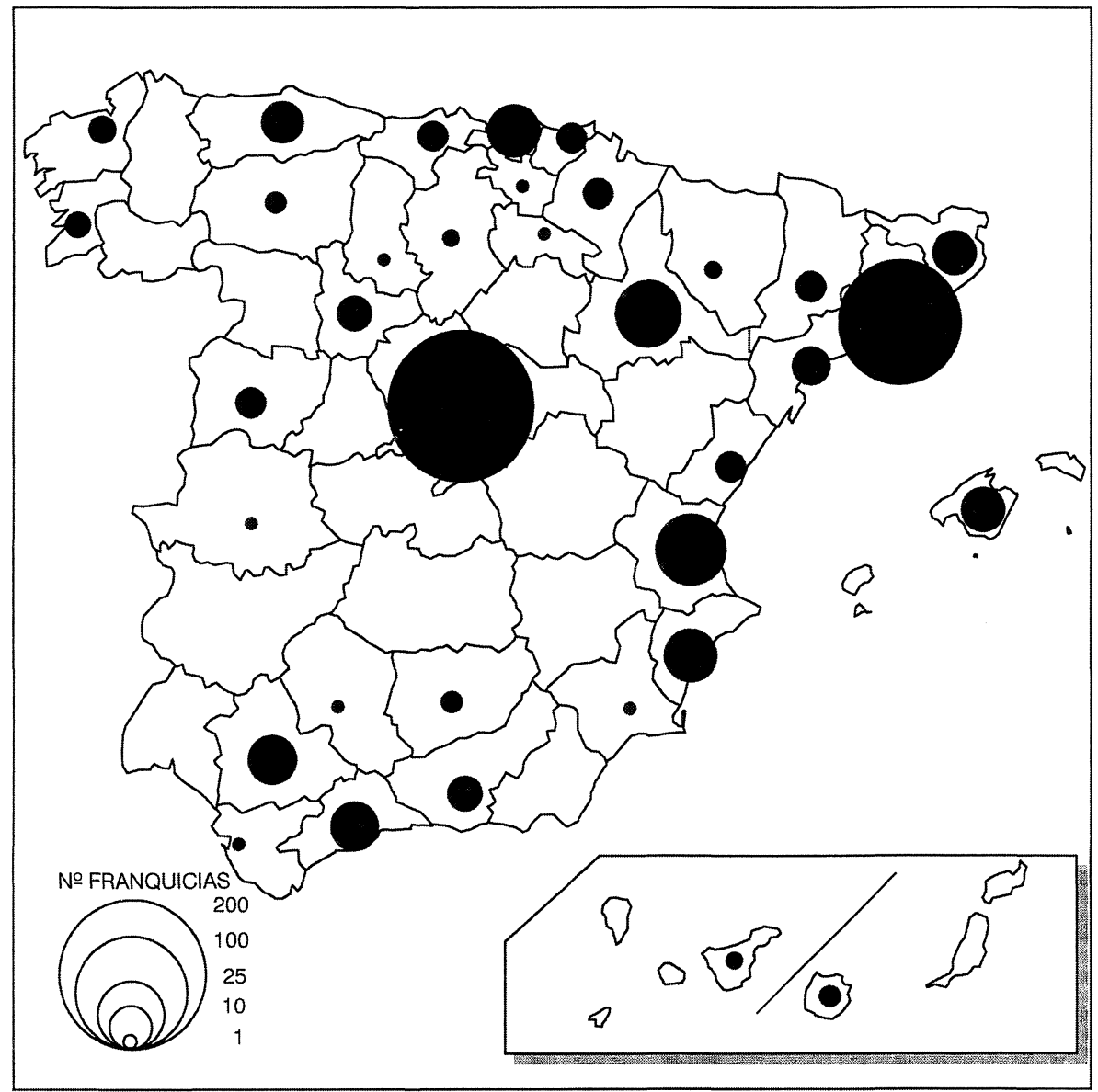

Fig. 1.-Localización provincial de los franquiciadores en 1997.

redes más extensas y consolidadas. A notable distancia se sitúan la Comunidad Valenciana y Andalucía (13,16\% de las franquiciadoras, que controlan el $8,12 \%$ de los locales), lo que parece corroborar el desplazamiento del centro de gravedad de la economía española en dirección al Mediterráneo, en detrimento de las regiones atlánticas e interiores. Ese desequilibrio resulta aún más evidente al utilizar unidades espaciales de menor dimensión como las provincias (figura 1). Se pone así de manifiesto la hegemonía de Madrid (240 enseñas, que controlan 9.346 esta- 
blecimientos) y Barcelona (203 y 7.901 respectivamente), muy por encima de las 48 provincias restantes, que apenas albergan un $30 \%$ de las enseñas. Entre estas últimas, se reproduce el mayor dinamismo relativo de las provincias situadas en esa Y griega que, desde el País Vasco, se prolonga por el eje del Ebro hasta alcanzar el eje Mediterráneo, mientras son 14 las provincias que no cuentan con ninguna enseña, dispuestas mayoritariamente en torno a Madrid.

Pero la verdadera medida de la polarización sólo se logra cuando se desagregan los datos a escala municipal (cuadro IV) y se constata que las siete ciudades con mayor número de franquiciadores, equivalentes al $59,44 \%$ del total, corresponden a las siete ciudades centrales de las aglomeraciones metropolitanas que en España superan el millón de habitantes. A éstas les siguen algunas ciudades medias que son también capitales de provincia, situadas principalmente en las regiones mediterráneas, y diversos municipios metropolitanos del entorno madrileño (Pozuelo de Alarcón, Alcobendas, Coslada, Las Rozas...) o barcelonés (Terrassa, Castelldefels, Cornellá de Llobregat...).

CUADRo IV (continuación)

DISTRIBUCIÓN MUNICIPAL DE LAS ENSEÑAS EXISTENTES EN 1997

\begin{tabular}{|c|c|c|c|c|c|}
\hline Municipios & $\begin{array}{c}\text { N. }{ }^{\circ} \text { Ense- } \\
\text { ñas }\end{array}$ & $\begin{array}{l}\text { N. }{ }^{\circ} \text { Esta- } \\
\text { blecim. }\end{array}$ & Municipios & $\begin{array}{c}\text { N. }{ }^{\circ} \text { Ense- } \\
\text { ñas }\end{array}$ & $\begin{array}{l}\text { N. }{ }^{\circ} \text { Esta- } \\
\text { blecim. }\end{array}$ \\
\hline Madrid & 194 & 8.084 & Granada & 5 & 47 \\
\hline Barcelona & 136 & 4.189 & Lleida & 5 & 66 \\
\hline Zaragoza & 24 & 528 & Pamplona & 5 & 48 \\
\hline Valencia & 21 & 532 & Salamanca & 5 & 105 \\
\hline Bilbao & 14 & 424 & Alcobendas & 5 & 219 \\
\hline Sevilla & 10 & 208 & Cornellá & 5 & 239 \\
\hline Málaga & 7 & 137 & Alicante & 4 & 39 \\
\hline Palma Mallorca & 7 & 310 & Calviá & 4 & 51 \\
\hline Valladolid & 7 & 43 & Coslada & 4 & 108 \\
\hline Pozuelo Alarcón & 7 & 216 & Figueres & 4 & 42 \\
\hline Tarrasa & 7 & 404 & Hospitalet & 4 & 659 \\
\hline Oviedo & 6 & 72 & Las Rozas & 4 & 99 \\
\hline Castelldefels & 6 & 41 & Otros municipios & 148 & 4.177 \\
\hline Castellón Plana & 5 & 42 & Total & 684 & 22.846 \\
\hline
\end{tabular}

Fuente: Guías de Franquicias 1998, y elaboración propia. 
Esa hegemonía de ambas metrópolis alcanza su máximo exponente en el caso de las franquicias de capital extranjero, que localizan 63 de sus sedes en la aglomeración de Barcelona y otras 48 en la de Madrid, lo que representa el $80 \%$ de las 140 contabilizadas. Puede constatarse un comportamiento espacial muy distinto entre las empresas de origen estadounidense y las de origen europeo. Mientras las primeras eligen la capital del Estado para instalarse ante su escaso conocimiento del territorio y las mayores facilidades que aquí encuentran para articular su red de establecimientos, tanto dentro como fuera de España, las segundas optan mayoritariamente por Barcelona, situación que puede relacionarse con una buena accesibilidad y una mayor tradición de implantación en Cataluña, donde ya operaban numerosas firmas industriales y de servicios procedentes de esos mismos países.

b) Localización de los establecimientos franquiciados. La gran cantidad de pequeñas unidades empresariales existente y el hecho de que la información disponible proceda de las franquiciadoras, hace que este aspecto resulte mucho más difícil de precisar que el anterior, aún siendo el más importante desde la perspectiva de los consumidores o del planeamiento urbano. Pueden, no obstante, apuntarse algunas tendencias significativas, que deberán ser objeto de investigaciones posteriores de carácter monográfico.

La localización regional de los establecimientos (cuadro III) muestra un reparto algo menos desequilibrado que el correspondiente a las enseñas, con una clara primacía de Cataluña $(31,69 \%)$, que duplica con creces la proporción correspondiente a Madrid $(14,92 \%)$ y triplica la de Andalucía (10,24\%), que en este caso supera a la Comunidad Valenciana $(8,92 \%)$. Por su parte, las Comunidades uniprovinciales, junto con Extremadura, se sitúan en los niveles más bajos, al no alcanzar en ningún caso el $2 \%$ de los locales franquiciados existentes en España. Si se comparan esas cifras con la cuota de mercado correspondiente a cada región en 1996, según el Anuario Comercial de España publicado por La Caixa, se pone de manifiesto una evidente correlación, habitual en actividades que, en su mayor parte, están en contacto directo con los clientes y atienden la demanda de bienes finales generada por esa población, con áreas de mercado generalmente limitadas. Pero una observación más atenta, que relacione ambos indicadores mediante un cociente de localización, pone en evidencia un comportamiento espacial algo más complejo en el caso de las franquicias, que muestran una presencia superior 
a la que les correspondería en función de la capacidad de compra en aquellos territorios más urbanizados, con alto nivel de renta, una destacada presencia del turismo y mayor difusión de hábitos de consumo procedentes del exterior, tal como ocurre en Cataluña, Madrid, el País Vasco, Baleares, Canarias o Cantabria (figura 2).

Aunque no se dispone de información para unidades espaciales de menor dimensión, el análisis de la población exigida por las enseñas para la

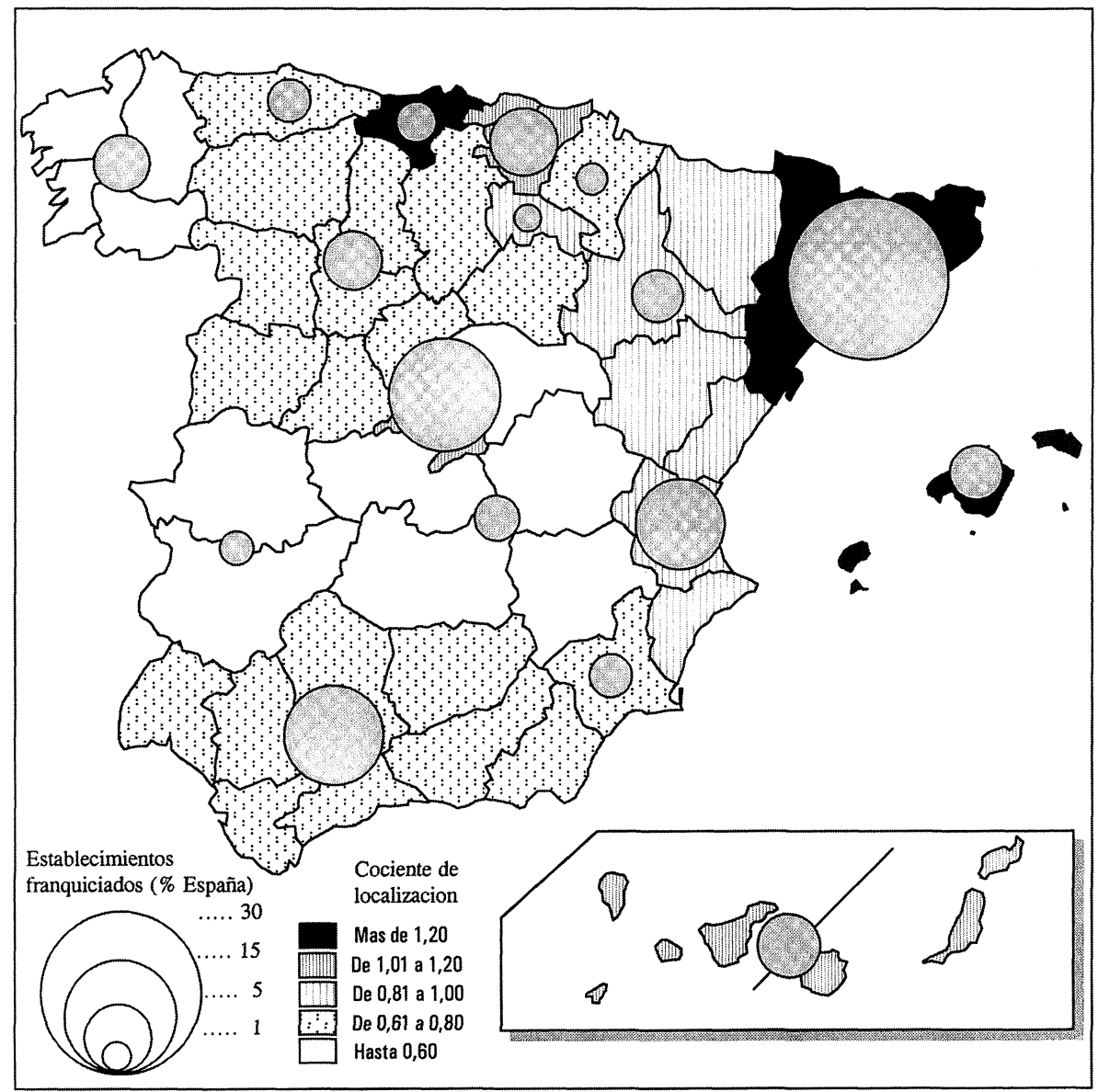

FIG. 2.-Distribución regional de los establecimientos franquiciados en 1997. 
instalación de establecimientos franquiciados constata que estamos en presencia de un fenómeno típicamente urbano, que excluye a las áreas rurales tanto por no alcanzar muchas veces el umbral mínimo de demanda que se exige, como por mantener unos comportamientos en materia de consumo algo diferentes aún a los urbanos, que no suscitan por el momento el interés de estas firmas. De este modo, de las 555 franquicias que ofrecen datos al respecto, tan sólo 31 de ellas $(5,5 \%)$ se muestran dispuestas a instalar algún local en núcleos que no alcancen los 10.000 habitantes, mientras 182 consideran esa cifra como umbral mínimo suficiente, 178 lo elevan a 50.000 habitantes, otras 130 lo hacen hasta los 100.000 habitantes, y tan sólo 34 exigen un mínimo de 200.000 residentes en el área.

c) La construcción de un espacio de redes. Desde la perspectiva de la geografía empresarial, resulta de particular interés considerar la evolución espacio-temporal de los diversos tipos de franquicias, aspecto para el que se dispone de información obtenida mediante encuesta a diversas cadenas que operan en España, lo que permite detectar una serie de regularidades que podrán precisarse mediante estudios monográficos posteriores.

En el período inicial de implantación sobre el territorio - que puede corresponder al nacimiento de la franquicia o a la llegada de una firma transnacional ya consolidada en su país de origen- la localización de los pocos establecimientos existentes se concentra en las principales metrópolis del sistema urbano, o en la ciudad de origen del empresario. Una segunda fase, de expansión o desarrollo, supone la incorporación de un elevado número de nuevos franquiciados y la apertura de nuevos locales, con altas tasas de crecimiento anual, que provocan la ampliación de la red mediante un proceso de difusión altamente selectivo, de carácter jerárquico (ciudades medias) o por contigüidad (coronas metropolitanas), pero reforzando la hegemonía de las principales metrópolis, donde suele existir aún cierta demanda por satisfacer.

Tan sólo en una tercera fase, de consolidación, que muy pocas franquicias han alcanzado por el momento en España, la aparición de rendimientos decrecientes en áreas de mercado cercanas a la saturación favorece una dispersión ya significativa, que alcanza a las ciudades de menor tamaño para conquistar así nuevos segmentos del mercado, lo que se acompaña a veces con la instalación de centros logísticos de aprovi- 
sionamiento para el conjunto de la red. Incluso en esta fase, algunos franquiciadores externalizan el riesgo de implantación en espacios con menor demanda potencial al destinarlos en exclusiva a los establecimientos ajenos (franquiciados), mientras localizan los propios en aquellas otras áreas más seguras y rentables. La dispersión no supone, por tanto, una disminución significativa de la estricta jerarquización interna existente en el interior de la red, vinculada a criterios objetivos de tamaño-accesibilidad, junto a otros subjetivos de valoración espacial-seguridad. Debido a la juventud del fenómeno, no se han encontrado por el momento ejemplos representativos de enseñas en fase de declive, si bien existen bastantes ejemplos de desapariciones tras un corto ciclo de vida.

\section{Conclusiones}

En resumen, las franquicias aparecen como un modelo de organización empresarial dentro del sector de la distribución, que experimenta una rápida expansión en todas nuestras sociedades, con tendencia a aumentar su importancia económica y su presencia en el paisaje urbano durante los próximos años. Por esa razón, resulta un objeto de estudio de evidente interés, tanto desde la perspectiva del nuevo modelo de organización económico-territorial, como desde la correspondiente a los cambios en las prácticas de consumo y de uso del espacio.

Además de proponer una interpretación de carácter teórico sobre su significado y las verdaderas razones de su espectacular crecimiento reciente, que aspira a servir para su debate y contrastación, el análisis iniciado para el caso español permite comprobar que se trata de un fenómeno contradictorio, alejado de esa visión excesivamente plana y optimista que destilan buena parte de los textos existentes sobre la materia, que se presta por eso a valoraciones diferentes en función de su desigual impacto sobre las empresas participantes, las que quedan al margen, los ciudadanos y los territorios. Sin entrar ahora en esas valoraciones, desde una perspectiva de conjunto pueden ofrecerse algunas ideas básicas para el debate:

- Frente al aumento de eficiencia y productividad que supone la incorporación de innovaciones en actividades generalmente tradicionales, la franquicia puede representar una competencia creciente para el pe- 
queño comercio minorista que, junto con la planteada por las grandes superficies comerciales, agudice su crisis y la consiguiente destrucción de empleo, ofreciendo así un saldo final menos favorable.

- Frente a las oportunidades que se abren para las PYMEs, tanto en su vertiente de franquiciador como de franquiciado, al permitir su incorporación a mercados de primer nivel, facilitar la difusión de conocimientos e innovaciones, o posibilitar su internacionalización, la evidencia de una creciente dependencia de numerosas empresas minoristas respecto a grandes grupos que controlan segmentos crecientes de la distribución, organizan redes fuertemente jerarquizadas y contribuyen a estandarizar los consumos de poblaciones muy diversas.

- Frente al acceso a productos y servicios que las franquicias parecen ofrecer a territorios habitualmente marginados de los principales circuitos de distribución, la constatación de que se trata de un fenómeno muy selectivo desde el punto de vista espacial, que excluye a buena parte del territorio por no ofrecer los requisitos exigidos por las enseñas, contribuyendo con ello a segmentar aún más la demanda.

En su análisis sobre la evolución reciente del sector de la distribución, Salgueiro (1996, XI) plantea la existencia actual de una «revolución en los puntos de venta, en las estructuras empresariales y en los hábitos de consumo», con procesos de concentración empresarial, innovación e internacionalización, que se reflejan en «nuevas técnicas de venta y exposición de los artículos, otros tipos de establecimientos con pautas de localización diferentes a las tradicionales, que acompañan la reestructuración funcional de las áreas urbanas en metrópolis policéntricas». Esa reestructuración interna, que corre paralela a un protagonismo creciente de las empresas de distribución dentro de los circuitos económicos, tiene en el desarrollo de las cadenas de franquicias una de sus manifestaciones más destacadas, tan contradictoria y dinámica como el propio sistema, que deberá ser objeto de una creciente atención en los próximos años.

\section{BIBLIOGRAFÍA}

Alonso PRIETo, M. (1997): Una franquicia para mi nuevo negocio. Tormo \& Asociados, Madrid.

ASOCIACIÓN ESPAÑOLA DE FRANQUICIADORES (1998): Libro oficial de la franquicia en España. AEF, Valencia. 
BARBADILlo Asociados (1998): Guía de Franquicias de España, 1998. Barbadillo Asociados Consultores, Madrid.

- (1998): Informe de situación de la franquicia en España. Barbadillo Asociados Consultores, Madrid.

BELUSSI, F. edit. (1992): Nuovi modelli d'impresa, gerarchie organizzative e impresa rete. Franco Angeli, Milán.

Bolea de ANTA, A. (1990): Los grandes de la franquicia. Ediciones de las Ciencias Sociales, Madrid.

BENKo, G. (1996): Economia, espaço e globalizaçâo na aurora do século XXI. Hucitec, Sâo Paulo.

BRown, S. (1992): Retail location: a micro-scale perspective. Avebury, Aldershot.

CACHINHO, H. (1994): «O comercio a retalho na cidade de Lisboa. Restruturaçâo economica e dinâmicas territoriais». Finisterra, vol. XXIX, n. ${ }^{\circ}$ 57, pp. 119-144.

CARRERAS, C. (1990): «Superficies comerciales como manifestación de la sociedad del bienestar». En Primeras Jornadas de Geografía y Comercio: Grandes Superficies Comerciales. UGI-Universidad Complutense, Madrid, pp. 37-60.

CASTELLS, M. (1997): La era de la información. Economía, sociedad y cultura. Volumen I: La sociedad red. Alianza Editorial, Madrid.

DAwson, J. A. edit. (1980): Retail geography. Croom Helm, Londres.

DAWSON, J. A.-BURT, S. L. (1988): The evolution of european retailing. ICL, Slough.

DiCKEN, P. (1998): Global shift: Transforming the world economy. Paul Chapman, Londres, $3 .^{\mathrm{a}}$ edic.

DíEZ de CASTRo, E.-Galán, J. L. (1998): Práctica de la franquicia. McGraw Hill, Madrid.

Flechoso, J. J. (1997): El libro de las franquicias. Biblioteca Nueva, Madrid.

GÁmIR, A. (1997): «Los procesos de cambio en los servicios personales y el comercio: autoservicio, telecompra y teleservicio». Boletín de la Asociación de Geógrafos Españoles, n. ${ }^{\circ} 24$, pp. $13-28$.

García BALLESTERos, A. (1998): «Nuevos espacios del consumo y exclusión social». Anales de Geografía de la Universidad Complutense, n. ${ }^{\circ} 18$, pp. 47-63.

GutiéRRez PuEBla, J. (1998): «Redes, espacio y tiempo». Anales de Geografía de la Universidad Complutense, n. $^{\circ}$ 18, pp. 65-86.

HARRISON, B. (1994): Lean and mean: the changing landscape of corporate power in the age of flexibility. Basic Books, Nueva York.

HARVEY, D. (1990): The condition of post-modernity. Blackwell, Oxford.

HuSSON-DUMOUTIER, A.-OlIVIER, B. (1993): Distribution, franchise et partenariat en Europe. Assemblée des Chambres Françaises de Commerce et de l'Industrie, París.

MEditerRáNEA DE FRANQUicias (1998): La franquicia en España hoy. Mediterránea de Franquicias, Alicante.

MÉNDEz, R. (1997): Geografía económica. La lógica espacial del capitalismo global. Ariel, Barcelona.

MÉRENNE-SCHOUMAKER, B. (1996): La localisation des services. Nathan, París.

Miquel, S.-PARRA, F.-L'Hermie, C.-Miquel, M. J. (1996): Distribución comercial. ESIC Editorial, Madrid.

Moreno, A.-Escolano, S. (1992): El comercio y los servicios para la producción y el consumo. Síntesis, Madrid.

RAAB, S. S.-MATUSKY, G. (1997): Franquicias. Cómo multiplicar su negocio. Limusa, México.

RIGOL, J. (1992): La franquicia: una estrategia de expansión. Escuela de Administración de Empresas, Barcelona.

Salgueiro, T. B. (1996): Do comércio à distribuiçâo. Roteiro de uma mudança. Celta Editora, Oeiras. 
Tormo \& Asociados (1998): Guía de Franquicias, 1998. Tormo y Asociados, Madrid.

VÁZqUEZ, R.-TRESPALACIOS, J. A. (1997): Distribución comercial: estrategias de fabricantes $y$ detallistas. Civitas, Madrid.

VELTZ, P. (1993): Logiques d'entreprise et territoires: les nouvelles régles du jeu. En M.SavyP.Veltz dirs. Les nouveaux espaces de l'entreprise. DATAR/Editions de l'Aube, Marsella, pp. 47-79.

(1998): Mundialización,ciudades y territorios. Ariel, Barcelona.

ABSTRACT: Over the last few years, the phenomenon of franchise as a new way of doing business has been undergoing a notable increase in Spain, with growth annual rates of 40 per cent. As a result, Spain's retail trade is suffering considerable transformations and growing even closer a similar profile to that dominant in other countries of the EU. The globalisation of distribution activities, management innovations, creation of networks organisations, changes in spatial localisation, or the progress of standarisation are the consequences. Behind this conceptual structure, the paper attempt to demonstrate how the franchise networks are being implemented in Spain, what their main features are and what behaviour they follow as regards distribution of franchises throughout the territory and within the major cities.

RESUMEN: El consumo es la base del desarrollo económico y, por tanto, también del avance social. Las necesidades primarias del Hombre constituyen su punto de partida, complicadas y ampliadas después por las que tienen como razon de ser el desenvolvimiento cultural. Pero el consumo y sus frutos, el intercambio mercantil y social, tienen su principal instrumento en la ciudad, tanto en su origen como en sus sucesivas etapas evolutivas. Las diferencias tanto temporales como espaciales y no menos sociales. Un ejemplo puede encontrarse en España pase a su retraso en su evolución hacia el consumo en masa. El consumo, como la ciudad y los medios económicos y culturales, están hoy muy afectados por la «globalización» creciente de la Humanidad.

PalabRaS Clave: Consumo. Comercio. Etapas urbanas. España. Globalización. 